\title{
HEALTH POLICY, HEALTH SYSTEMS RESEARCH AND ANALYSIS CAPACITY ASSESSMENT OF THE SCHOOL OF PUBLIC HEALTH, UNIVERSITY OF GHANA
}

\author{
I. A. AGYEPONG ${ }^{1,2}$, K. ANNIAH ${ }^{1}$, M. AIKINS ${ }^{1}$, P. AKWEONGO ${ }^{3}$, R. ESENA ${ }^{1}$ and T. \\ MIRZOEV $^{4}$
}

${ }^{1}$ Health Policy, Planning and Management Department, University of Ghana, School of Public Health, P. O. Box LG13, Accra, Ghana ${ }^{2}$ Julius Global Health, HP STR.6.131, P.O. Box 85500, 3508 GA Utrecht, The Netherlands ${ }^{3}$ Epidemiology Department, University of Ghana, School of Public Health, P.O. Box LG 13, Legon, Accra, Ghana ${ }^{4}$ Nuffield Center for International Health and Development, Leeds Institute of Health Sciences, University of Leeds, G16, Charles Thackrah Building, 101 Clarendon Road, Leeds, LS2 9LJ, UK.

DOI: http://dx.doi.org/10.4314/gmj.v49i3.12

Corresponding author: Dr Irene Akua Agyepong

E-mail:iagyepong@hotmail.com

Conflict of interest: None declared

\section{SUMMARY}

Introduction: Health Policy and Systems Research and Analysis (HPSR\&A) is an applied science that deals with complexity as it tries to provide lessons, tools and methods to understand and improve health systems and health policy. It is defined by the kinds of questions asked rather than a particular methodology. Objective: Our objective was to assess capacity and capacity strengthening needs for HPSR\&A conduct and teaching in the University of Ghana School of Public Health (UG-SPH). We conceptualized dynamically inter-related levels of capacity as contextual, institutional and individual.

Methods: The study had a cross sectional, mixed methods design. Data collection involved desk review, ,an in-depth interview, focus group discussions (FGD) and an interviewer administered questionnaire with closed and open ended items. Netmap was used as a tool in the FGD.

Findings: At all levels, HPSR\&A capacity exists in Ghana but is somewhat fragile. The fragility reflects in part contextual challenges related to national income and priorities as well as the fact that globally HPSR\&A remains an emerging field. At the contextual level, Institutions involved in some way or other in HPSR\&A were part of larger organizations with broader mandates. Only a handful of SPH staff indicated that they specifically do teaching and /or research related to HPSR\&A.

Conclusion \& Recommendations: There is a need to raise awareness of the field of HPSR\&A and its potential contributions to health sector development; build upon already existing contextual, institutional and individual capacity; and also attract and develop the next generation of researchers and teachers.
Keywords: Health Policy, Health Systems, Research, Teaching, Capacity

\section{INTRODUCTION}

Health Policy and Systems Research and Analysis (HPSR\&A) is an applied science that provides lessons, tools and methods to analyze and improve health systems and decision making (policy) within health systems. HPSR\&A is also referred to in the literature as Health Systems Research (HSR) and Health Policy and Systems Research (HPSR). It also encompasses the field referred to as Health Services Research. Conceptualizing health systems is important to understanding what HPSR\&A is. Murray and Frenk ${ }^{1}$ define the boundaries of a health system as including all the resources, actors and institutions related to the financing, regulation and provision of health actions. Health actions are any set of activities whose primary intent is to improve or maintain health. Hsiao ${ }^{2}$ similarly conceptualizes a health system as a set of relationships in which the means (structural components) are causally connected to the ends (goals) - within the boundaries of all activities whose primary purpose is to promote, restore or maintain health. The World Bank ${ }^{3}$ in their strategy for health nutrition and population, describe health systems as " ...all country activities, organizations, governance arrangements, and resources (public and private) dedicated primarily to improving, maintaining, or restoring the health of individuals and populations and preventing households from falling into poverty (or becoming further impoverished) as a result of illness." 
Health systems are complex, multidimensional domains of actors and actions, which produce outcomes that societies value. ${ }^{4}$ Stakeholders include patients, various types of health-care providers, payers, purchaser organizations, regulators, government and the broader citizenry. 5 People and their power in deciding, shaping and responding to change are central to health systems. ${ }^{6-8}$ Health systems are dynamic, evolving, fluid, complex and adaptive rather than static entities. They are governed by feedback, and organize and adapt based on experience.

Outcome goals of health systems are to: improve health; be responsive to the legitimate non-health expectations of the population e.g. prompt treatment, treatment with dignity; and ensure fairness in financial contributions. The level of goal attainment e.g. life expectancy, maternal mortality, infant mortality; as well as the distribution of the goal within the population (equity) are important.

HPSR\&A concerns itself with the investigation of and methodologies for investigating the processes by which societies organize their health systems to achieve collective health goals. This includes the interaction of actors in the processes, decision making at all levels (policy) and effects on outcomes. HPSR\&A is a multi and inter-disciplinary predominantly social science. It draws upon a blend of disciplines such as economics, sociology, anthropology, political science, and epidemiology in its methods. ${ }^{9}$ This means that it does not have a single methodological gold standard. The question asked defines whether research can be classified as HPSR\&A or not; and since a variety of questions can be asked, drive the decision as to the most appropriate methodology. ${ }^{10}$ Questions asked by HPSR \&A cover a wide range of issues related to the functioning of health systems, such as service delivery, financing, governance and resources. HPSR\&A capacity though growing, remains under developed in Low and Middle Income Countries (LMIC). ${ }^{11,12}$

The Institutes of Medicine defined public health as "what we, as a society do collectively to assure the conditions in which people can be healthy".13 HPSR\&A with its focus on the more upstream aspects of health, organizations and policies, is one of its essential disciplines. It is natural therefore that Schools of Public Health in tertiary academic institutions play critical roles in the development of academic and research capacity related to this field. Capacity is the ability to carry out stated objectives, to do or perform. It is a function of the skills of individuals, the tools at their disposal and the ability of the organizations or institutions within which they work as well as the broader context to support performance. ${ }^{14-19}$ Capacity is a dynamic and complex relationship within and between different levels and elements of organisations, individuals and context. Levels of capacity can be described as the individual, organizational and institutional and the wider environmental or contextual. Capacity is evidenced by processes and structures as well as outputs. ${ }^{20-22}$ In relation to HPSR\&A teaching and conduct; outputs can include successful grant applications, qualifications obtained, publications, conference presentations, and research influencing policy and practice. Capacity assessment research can help identify capacity assets, which can often exist but be constrained - and therefore need to be unleashed as part of capacity strengthening.

Our objective was to assess capacity and capacity strengthening needs for HPSR\&A conduct and teaching in the University of Ghana School of Public Health (UG-SPH) to inform action for building the field. Drawing upon the literature we conceptualized three inter-related levels of factors that influence capacity to teach and conduct HPSR\&A as in Figure 1. We had four specific objectives related to this conceptualization. Firstly we aimed to describe the wider context of relevance to HPSR\&A conduct and teaching in UG-SPH. Secondly we aimed to assess the institutional and thirdly individual staff capacity within the UG-SPH for HPSR\&A conduct and teaching. Finally we aimed to understand inter-relationships between the levels. Superimposed on the framework of three levels of capacity, we explored five thematic areas of (1) Leadership and Governance, (2) HPSR\&A teaching and conduct (3) research quality assurance, (4) communications, networking and Getting Research Into Policy and Practice (GRIPP); and (5) supporting resources for HPSR\&A.

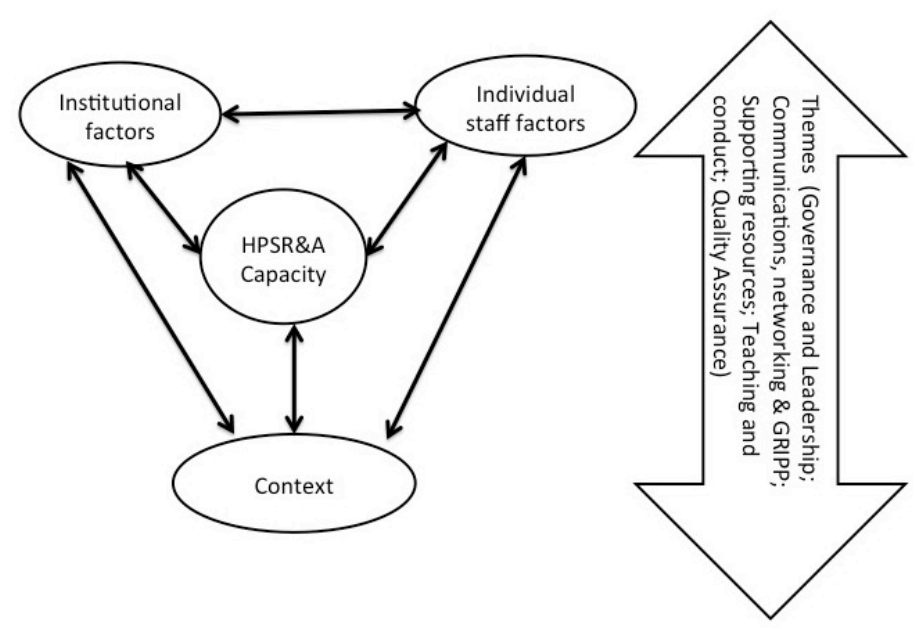

Figure 1 Conceptual framework for the needs assessment 
Our objectives were set within the framework of the Consortium for Health Policy and Systems Analysis in Africa (CHEPSAA). CHEPSAA is a European Union funded consortium of 7 universities within 5 African countries, of which the University of Ghana is one; and 4 European universities within 3 countries. CHEPSAA aims to contribute to the improvement of health in subSaharan Africa by supporting health system strengthening though increasing sustainable African capacity to produce and use high quality health policy and systems research and analysis (HPSR\&A) by harnessing synergies within the Consortium.

\section{METHODS}

This cross sectional study was conducted between March and December 2011 using mixed methods of data collection. A non-exhaustive desk review of grey and published literature was conducted to map context. Documents were obtained through Google and PubMed searches and key informants. Additionally we conducted organizational and individual assessment using an in-depth interview with the Dean UG-SPH; three focus group discussions (FGD) with Ministry of Health staff, past MPH students in practice and faculty of HPPM; and a UG-SPH staff interviewer administered questionnaire. Sixty-seven (67) UG-SPH teaching and research, administration and support staffs ( $86 \%$ of all staff) were interviewed. Variables in the questionnaire included staff status (full time, part time or contract); job roles, types, content and management of teaching and research, academic training and experience, working conditions, career development needs and opportunities. Topics explored in the FGD and in-depth interview were related to the five thematic areas.

Net map $^{23}$ was used as a tool in the FGD to help map actors and their roles and linkages in HPSR\&A conduct and teaching. Net Map is a flexible tool that helps understand, visualize and discuss situations in which different actors influence outcomes. Working with a note taker, the facilitator asked participants to brainstorm all key actors around a particular question or issue and the links between them. The results were diagrammed on a flip chart, with different colour lines indicating relationships and networks. Participants then rated the relative importance of actors with regard to the issues and linkages.

Qualitative interviews were tape recorded and transcribed. Qualitative data - including open-ended questions in the staff questionnaire was manually analysed for themes, commonalities and contrasts. The responses to the open ended questions were typed into Excel for coding and sorting into themes and categories. Quantitative data was analysed using STATA and results presented in graphs, frequency and cross tables. Triangulation of information on the same topic from the different data collection methods was used during analysis to generate a richer understanding of complex processes and also as part of the process of ensuring reflexivity and rigor in the conclusions.

The investigators did all the qualitative interviewing while interviewers were recruited and trained to administer the staff questionnaire. All interviews were done with informed consent. Ethical clearance was obtained from the Research and Development Division of the Ghana Health Service.

\section{FINDINGS}

We present our findings within the framework of three levels of capacity and five thematic areas. To avoid being repetitive, apart from the thematic area of governance and leadership which we discuss at both the contextual and the SPH institutional level; the thematic areas we focus on at each level are those whose inputs, processes and outputs are largely at that level despite having effects across levels.

\section{CONTEXTUAL LEVEL CAPACITY Institutions}

Networking and exchange between institutions can be an important part of capacity building. We therefore tried to map major institutional actors in the field of HPSR\&A in Ghana. We did not find any dedicated HPSR\&A conduct and /or teaching institutions. Institutions that were involved in HPSR\&A were part of larger organizations with a broader mandate. These organizations can be classified as primarily engaged in research or both teaching and research. Additionally, they can be classified as academic, practice or purely research organizations. This is summarized as a matrix in Table 1.

The Centre for Scientific and Industrial research (CSIR) was established by law in the nineteen sixties as the body with oversight for scientific and industrial including medical research in Ghana. It has a collection of institutes covering science, environment, food and nutrition and Information and Communication Technology and a Science \& Technology Policy Research Institute (STEPRI) to provide research support for national science and technology policy development, monitoring and evaluation. It is expected to link up with the Ministries of Trade and Industries, Science and Technology, the National Investment Centre, Ghana Standards Board, Registrar-General's Department, research institutions and universities. The constitutional mandate for coordinating and regulating all research in Ghana rests with the CSIR. 
At the time of the study its oversight and coordination

research appeared to be dormant.

functions for as well as active involvement in health

Table 1 Context mapping of institutions doing some HPSR\&A type research

\begin{tabular}{|c|c|c|c|}
\hline & \multicolumn{2}{|c|}{ PRIMARY ORGANIZATIONAL MANDATE AND FOCUS } \\
\hline & & Research & Teaching \& Research \\
\hline \multirow{3}{*}{ 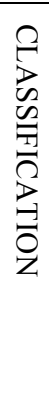 } & Academic & $\begin{array}{l}\text { Special institutes within universities e.g. Noguchi } \\
\text { Memorial Institute for Medical Research } \\
\text { (NMIMR), Centre for Tropical and Clinical } \\
\text { Pharmacology (CTCP) of the University of Ghana } \\
\text { Medical School }\end{array}$ & $\begin{array}{l}\text { Universities (Departments and Schools } \\
\text { e.g. School of Public Health, the Business } \\
\text { school, Ghana Institute of Management } \\
\text { and Public Administration) }\end{array}$ \\
\hline & Practice & $\begin{array}{l}\text { Research and Development Division (RDD) of the } \\
\text { Ghana Health Service } \\
\text { Ghana Statistical Services (GSS) }\end{array}$ & \\
\hline & $\begin{array}{l}\text { Purely } \\
\text { Research }\end{array}$ & Centre for Scientific and Industrial research (CSIR) & \\
\hline
\end{tabular}

The Ghana Health Service (GHS) Research and Development Directorate (RDD) and its district based research stations are very active in research including some HPSR\&A. Their mandate is to generate information through research to strengthen decision making, support priority setting and efficient resource allocation; inform health intervention planning and implementation in order to deliver better health services to improve health status of the Ghanaian population.

The Ghana Statistical Service (GSS) has the mandate to conduct national surveys for government. In addition to external partners, the GSS collaborates with research institutions in Ghana such as the Ghana Health Service Research and Development Directorate (GHS RDD), and the Noguchi Memorial Institute for Medical Research (NMIMR) of the University of Ghana for the conduct of surveys such as the Ghana Demographic and Health Survey (GDHS). It also generates other research data of relevance to HPSR\&A such as the Core Welfare indicators Questionnaire and the Ghana Living Standards survey data.

Universities in Ghana (public and private) operate under the oversight of the National Council for Tertiary Education (NCTE) of the Ministry of Education. ${ }^{24}$ The two oldest universities; the University of Ghana (UG) established in 1948 and the Kwame Nkrumah University of Science and Technology (KNUST) established in 1962 have relatively well known colleges, departments and institutes engaged in some HPSR\&A related teaching and conduct. The Kumasi Centre for Collaborative Research into Tropical Medicine (KCCR) of the KNUST is a 20-year collaborative project (1997 - 2016) between the School of Medical Sciences (SMS) of KNUST, the Bernhardt Nocht Institute for Tropical Medicine, University of Hamburg, Germany; and the Ministry of Health, Ghana. The sponsors are the Ghana Government, $\mathrm{MOH}$ Ghana, the City of Hamburg, and the Federal German Government. The focus of the project is research into tropical diseases and research capacity building.

The Noguchi Memorial Institute for Medical Research (NMIMR) is a semi-autonomous biomedical institution that is part of the College of Health Sciences of the University of Ghana. Its mandate is to conduct research into health problems of public health importance. It collaborates with other departments and institutes in the University of Ghana and other local and international research institutions. Apart from basic biomedical and epidemiological research, it does some HPSR\&A. Examples include the IMPACT project that researched maternal survival and related policies; access to medicines research and other social science and malaria research. Another semi-autonomous institute within the University of Ghana that conducts some HPSR\&A is the Institute for Statistical, Social and Economic Research (ISSER). The department of community health of the University of Ghana Medical School (UGMS) has in the past engaged in some HPSR\&A type work in the Danfa project.

\section{THEME: CONTEXTUAL LEVEL GOVERNANCE AND LEADERSHIP}

Essential stewardship and governance skills in a national health research system include capacity to formulate a vision, mission, goal and policy; to prioritize, address ethical considerations, collect, analyse and use information to assess and evaluate the various aspects and steps in the research process and 
design and implement policies which effectively address inequities in health research, including the financing of research, setting the research agenda, and knowledge publication and utilization. We did not find any clear national mechanisms for priority setting, coordinating research agendas and harnessing them to a regularly updated national health research agenda and national development though several $\mathrm{MOH}$ documents suggested that the importance of research is recognized. $^{25,26}$ It appeared that implementation has lagged behind the stated intent.

\section{THEME: COMMUNICATIONS, NETWORKING AND GETTING RESEARCH INTO POLICY AND PRACTICE (GRIPP) \\ Communication and Networking}

Figure 2 summarizes the Net map session with SPH faculty on actors in HPSR\&A, how they link with each other and the UG-SPH. Actors identified included the contextual actors already described. Additionally, the Media, International Funders, International Non Governmental Organizations (NGO) such as the INDEPTH network, International Academic Institutions and the Community were mentioned. HPSR\&A links between the UG-SPH, MOH and its Agencies include teaching, conduct and financing of HPSR\&A as well as advice and information provision.
While some of the linkages between actors (e.g. teaching and conduct of research) were felt by respondents to be bi-directional (double headed arrows in Figure 2); others (e.g. finance, advice and information) were felt to be predominantly unidirectional (single headed arrows). For example, in teaching, the relationship is bi-directional. Staffs from the $\mathrm{MOH}$ and its agencies attend courses and programs in the SPH. At the same time, some staffs from the $\mathrm{MOH}$ and its agencies provide part time teaching within the SPH. In research, the relationship is unidirectional. UG-SPH conducts research within the health sector, but the health sector does not conduct research within UG-SPH. On the other hand, the health sector sometimes provides financing to the UG-SPH but not vice versa. The contextual actors also link with each other e.g. International Funders fund other research institutions and some $\mathrm{MOH}$ policy and program development and implementation.

Table 2 summarizes the consensus perceptions of participant in the Net map session, as to the relative importance of the contextual partners with regard to each issue. A ranking system with scores progressing from 1 to 5 where a score of (1) indicates 'Not important at all'; a score of (5) 'very important' was used.

Table 2 Ranking of perceptions of Relative Importance of contextual actors in relation to issues related to HPSR\&A by Health Policy, Planning and Management (HPPM) faculty

\begin{tabular}{|l|l|l|l|l|l|l|}
\hline \multirow{2}{*}{ Partners } & \multicolumn{6}{|l|}{ Issues \& relative importance of actor in relation to HPSA and the issue rating } \\
\cline { 2 - 8 } & Advise & Information & Finance & Teaching & Research & $\begin{array}{l}\text { Capacity } \\
\text { building }\end{array}$ \\
\hline $\begin{array}{l}\text { Wider University } \\
\text { of Ghana }\end{array}$ & 1 & 1 & 1 & 5 & 5 & 5 \\
\hline Media & 1 & 5 & 1 & 1 & 1 & 1 \\
\hline $\begin{array}{l}\text { International } \\
\text { funders }\end{array}$ & 5 & 4 & 5 & 1 & 5 & 4 \\
\hline $\begin{array}{l}\text { International } \\
\text { NGO (INDEPTH) }\end{array}$ & 5 & 4 & 5 & 1 & 5 & 4 \\
\hline $\begin{array}{l}\text { International } \\
\text { Academic } \\
\text { Institutions }\end{array}$ & 5 & 3 & 1 & 3 & 5 & 4 \\
\hline Community & 1 & 3 & 1 & 1 & 4 & 1 \\
\hline $\begin{array}{l}\text { Ministry } \\
\text { Health } \\
\text { Agencies }\end{array}$ & 4 & 4 & 3 & 4 & 4 & 4 \\
\hline
\end{tabular}




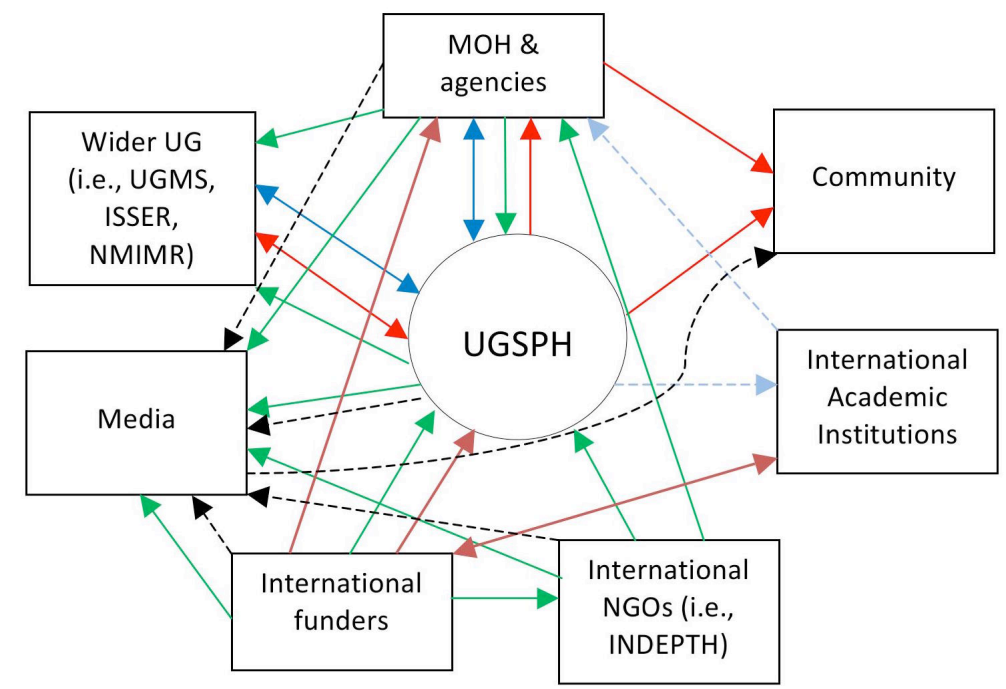

Legend:

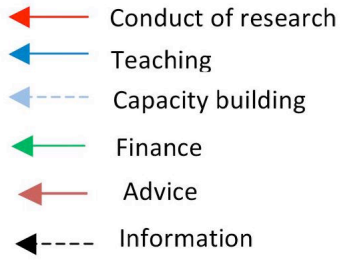

Figure 2 Key actors and their linkages from Netmap session

\section{GETTING RESEARCH INTO POLICY AND PRACTICE (GRIPP)}

We use the term "Getting Research Into Policy and Practice" and its acronym "GRIPP" to refer to the processes through which research informs and influences the health issues on which decisions are made i.e. the agenda; how and what kinds of decisions are made and how these decisions are implemented and sometimes modified in the course of implementation. The Net-Map session with past students of UG-SPH in Public Health practice and the FGD with senior staff of $\mathrm{MOH}$ focused on exploring actors, their linkages and networking related to these processes. The Net-Map is shown as Figure 3.

Institutions in the public sector identified as important in GRIPP were the Ministry of Health (MOH) and its implementation and regulatory agencies such as the Ghana Health Service (GHS), National Health Insurance Authority (NHIA), Food and Drugs Authority (FDA), Medical and Dental Council (MDC), Nurses and Midwives Council (NMC).
Important individual actors within these institutions varied from institution to institution. In the $\mathrm{MOH}$ they were the Minister, Chief Director and the Directors; while in the GHS, they were the Director General, national, regional and district level Directors. Health providers or frontline workers were also mentioned as important individual actors and more or less "policy practitioners" depending on the issue.

Non public sector institutions identified as important in the processes through which research influences policy and practice (GRIPP) included the Christian Health Association of Ghana (CHAG); Quasi-government agencies; Non Governmental /Civil Society Organizations (NGO/CSO); Private providers; Development partners and the media. Other ministries departments and agencies such as Education; Information services department; and the Ministry of Finance were also important. Respondents indicated that how involved actors were in these processes depended on the policy issue. Actors were linked through transmission of information, financing, giving of advice and technical assistance. 


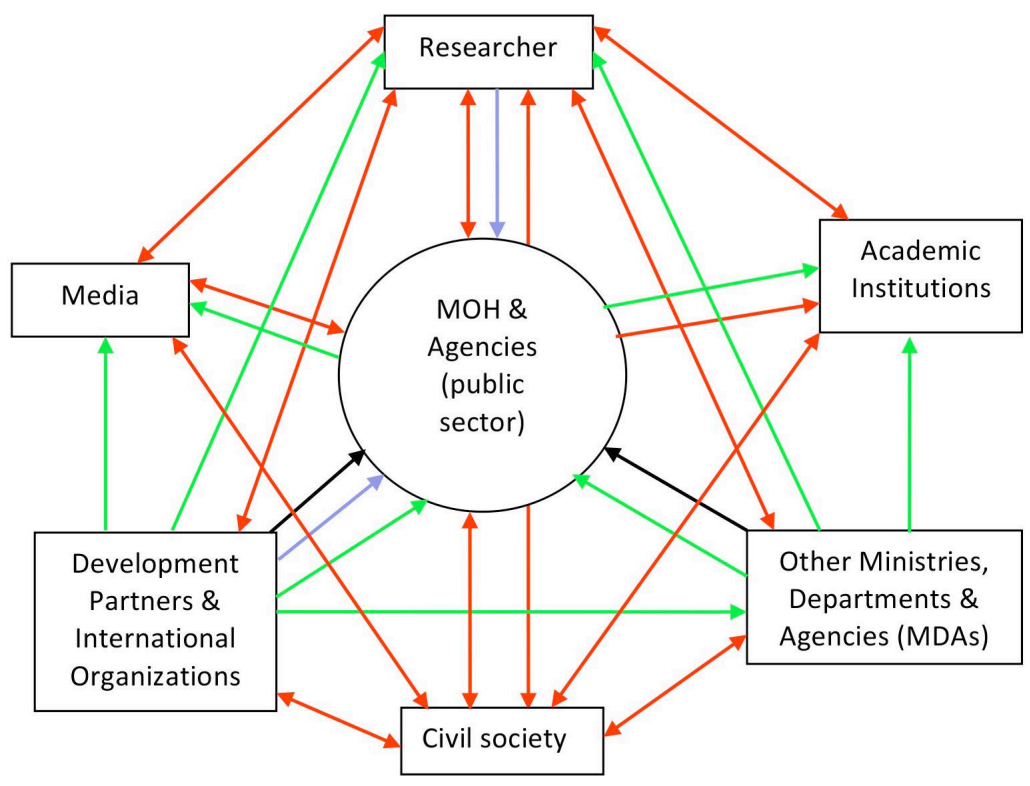

Legend:

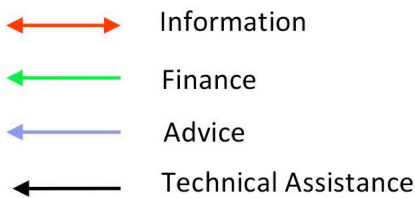

Figure 3 Netmap developed with Past MPH Graduates working in the Health Sector on identifying, describing and analysing relationships related to networking and GRIPP

\section{UG-SPH INSTITUTIONAL LEVEL CAPACITY}

\section{Theme: Institutional level Leadership and} Governance

The School of Public Health (SPH), established in 1994 , is one of the schools and institutes of the College of Health of Sciences (CHS) of the University of Ghana. The leader of the UG-SPH with the responsibility for its vision in the context of the vision of the university as a whole, as well it's day-to-day management is the Dean. He /She is accountable to the Provost of the CHS who in his/her turn is accountable to the Vice Chancellor. At the time of the study, the SPH had five departments namely Social and Behavioral Sciences (SOBS); Epidemiology and Disease Control (EPDC); Biostatistics, Basic Environmental and Occupational Sciences (BEOS); Population, Family and Reproductive Health (PFRH) and Health Policy, Planning and Management (HPPM); each with a head.
Due to shortage of full time staff when it started in 1994, the UG-SPH relied extensively on public health practitioners as part time faculty and student supervisors. As the school grew and acquired more full time staff, the use of part time staff in public health practice to support teaching and student supervision declined. The advantage has been that the school has staff whose time and outputs it has more control over, and less needs to pay part time staff allowances. The disadvantage is that public health is a professional as well as academic discipline and the school runs a risk of getting dissociated from professional public health practice. To counter this disadvantage, the leadership of the school at the time of the study indicated that there had been efforts to get staff actively engaging with public health practice and the health system. However it had not been very successful. There appeared to be a variety of reasons including lack of a structured program and incentives for engagement; and faculty overloaded with student teaching and supervision. 
Theme: Supporting Resources for HPSR\&A UG-SPH gets its Government of Ghana funding for recurrent expenditure from the National Council for Tertiary Education (NCTE) through the main university. Sources of this fund include consolidated taxes, the Ghana Education Trust Fund or GET Fund (a dedicated fund for the educational sector made up of 2.5\% Value Added Tax), and some donor funding. Additionally individual faculty related projects bring in some international funding. Funding specific for HPSR\&A conduct and teaching was not possible to determine.

At the time of the study, the Controller and Accountant General's Department (CAGD) paid UG-SPH staff salaries under a pilot of proposals for the University to become part of the CAGD system, a reform the university was not very keen on. All other staff salaries, were paid directly by the University using funds transferred from the NCTE.
The advantage of this system is that it gives the university better autonomy and flexibility in the control of its human resource budget.

The disadvantage is that there are sometimes reimbursement delays and the university has to take bank loans to advance pay its staff. The SPH having a different HR payment system had created some peculiar challenges. It was no longer possible to engage part time faculty and add their remuneration to the University wage bill. Staff incentives such as Rent allowance were not so easily reimbursed. The SPH had to get approval to engage new staff under a dual system of both the University and the CAGD processes.

Table 3 summarizes the staffing of the UG-SPH by category and by department at the time of the study in 2011. The University of Ghana requires doctoral level training to be employed as a lecturer or higher, classified as "academic staff". Tutors, teaching assistants and other research and teaching staff without doctoral level training are classified as "non academic staff".

Yes, I have adequate access to:

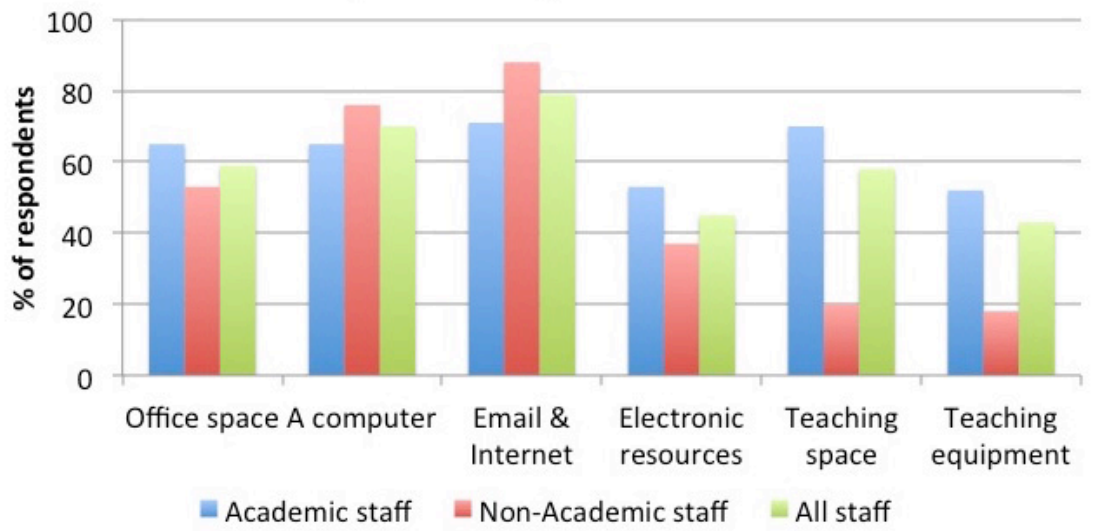

Figure 4 Infrastructure, equipment, tools and supplies access

Despite a vast improvement from its start in 1994 in a handful of loaned offices and shared lecture halls in the Institute of Statistical, Social and Economic research (ISSER) to the current situation where it has its own buildings; the School's infrastructure - both lecture hall and faculty office space as well as access to equipment, tools and supplies such as computers, internet, email and electronic resources including online journals were inadequate for its expanding needs. Figure 4 summarizes staff responses to the "yes" or "no" question: "Do you have adequate access to any of the following to support you in your job role" in reference to office space, computers, internet and email, electronic resources including online journals, teaching space and teaching equipment. Some staff in the category "non-academic /administrative" answered the question on access to teaching space and teaching equipment because non-academic staff such as assistant lecturers and tutors do some teaching.

Specific infrastructure constraints mentioned included inadequate office space and furniture, no kitchen or canteen, and some interruptions in Internet service and electricity supply. Regarding assets the school had that had not yet been fully exploited, staff felt that there was enough land to put up spacious offices, lecture halls and a canteen for staff. 
They also felt that benches and chairs could be provided for students under the trees; sandwich students could be allowed to utilize the classrooms during recess, and some office space created for part time staff.

\section{Theme: HPSR\&A Teaching and Conduct}

All MPH courses offered within the department of Health Policy, Planning and Management (HPPM) at the time of the study were HPSR\&A relevant. They were all 2 credit hours implying 26 hours of classroom contact time and about $12-24$ hours of reading and exercises.

Some MPH courses in other departments e.g. social science research methods, epidemiological research methods, were HPSR\&A relevant given the multidisciplinary nature of the field. Some short courses had modules with HPSR\&A related content. There were no doctoral level courses at the time of the study. Staff with PHD had mainly obtained them from institutions in Europe and North America.

Seven (7) staff (6 academic and 1 non-academic) indicated that they engaged in or supported HPSR\&A teaching and conduct. Of these, 5 were engaged in both HPSR\&A teaching and conduct, one in teaching and one in research only. Their teaching experience ranged from 2-12 years; while research experience ranged from 1-22 years. Five were involved in the setting assignments in HPSR\&A related teaching and 3 in obtaining and using student reviews of courses. Five were involved in new course development. One was involved in general management of HPSR\&A related courses in the UG-SPH such how courses linked to each another; and managing application for courses by students.

Apart from CHEPSAA, there were several HPSR\&A related projects in UG-SPH at the time of the study. Most were generating knowledge as well as contributing to staff development, recruitment and retention and involved partnerships with other institutions. The safety and effectiveness of antimalaria medicines in real life health systems (INESS), funded by the Bill and Melinda Gates Foundation involved the London School of Hygiene \& Tropical Medicine; the University of Cape Town; the Ghana Food and Drugs Authority and INDEPTH network sites in Ghana, Tanzania, Burkina Faso, and Mozambique. The Ghana Essential Health Intervention Project (GEHIP) aimed to strengthen health systems through improved leadership informed decisionmaking, integrated services and logistics and planned and coordinated resource allocation. Funding was from the Doris Duke Charitable foundation, and partners
Ghana Health Service, Ifakara Health Institute in Tanzania. The PERFORM project was focused on supporting Decentralized Management to Improve Health Workforce Performance in Ghana. Funding was from the European Commission (EC). Partners were the Liverpool School of Tropical Medicine, University of Leeds, University Of Dar Es Salaam; Makerere University and the Swiss Tropical and Public Health Institute. MASCOT (Multilateral Association for Studying Health Inequalities and Enhancing NorthSouth and South - South Cooperation) was funded by the EC.

Its objective was to stimulate links among countries from Europe, Africa and Latin America in efforts to address maternal and child health inequalities in low and middle-income countries and to provide evidence on best practices and policy advice for the development of future public health and health systems interventions. Partners were the Council on Health Research for Development, Euroquality SARL, Sociedade Portuguesa de Inovação, University Hospital Farhat Hached, Universidad Católica de la Santísima Concepción, National Institute of Public Health, National Institute for Medical Research, International Health Central American Institute Foundation and Health Action Partnership International.

\section{Theme: HPSR\&A Quality Assurance}

There were several mechanisms to ensure research and teaching quality assurance that also covered HPSR\&A. The Research and Development Division (RDD) of the Ghana Health Service (GHS) had an ethical review committee that the School of Public Health shared. All students conducting research were assigned academic supervisors and there were several seminars for students to present research proposals for review by student peers, faculty and stakeholders from the health sector. External examiners were involved in the final assessment of all dissertations and thesis. Methods courses also supported the development and quality of students' capacities. All courses taught in the SPH had to go through a review and approval process initially with academic review committees within the $\mathrm{SPH}$ and then in the wider university.

\section{Individual staff level capacity}

Table 4 summarizes data from the individual staff interviews. Approximately half of the staff interviewed (34/67) were academic staff. The rest were either administrative or non academic staff. Non academic and administrative staff were younger with a mean age (SD) of 34 (11) and a median age of 31; as compared to academic staff whose mean age (SD) was 47 (10) and median age 47 . 
Table 3 UG-SPH staffing by category and Department at the time of the study (2011)

\begin{tabular}{|c|c|c|c|c|c|c|c|c|c|c|c|c|}
\hline \multirow[b]{2}{*}{ Department $^{1}$} & \multicolumn{5}{|c|}{ Full time Staff with PHD or equivalent (Academic staff) } & \multicolumn{2}{|c|}{$\begin{array}{l}\text { Full time staff without PHD } \\
\text { (non academic staff) }\end{array}$} & \multirow{2}{*}{$\begin{array}{l}\begin{array}{l}\text { Total full } \\
\text { time staff }\end{array} \\
\begin{array}{l}\text { Total } \\
\text { staffing }\end{array}\end{array}$} & \multirow[t]{2}{*}{$\begin{array}{l}\text { Part time } \\
\text { staff }\end{array}$} & \multirow{2}{*}{$\begin{array}{l}\text { All staff } \\
\text { (full \& part } \\
\text { time) }\end{array}$} & \multirow{2}{*}{$\begin{array}{l}\text { No. Of } \\
\text { staff } \\
\text { interviewed }\end{array}$} & \multirow{2}{*}{$\begin{array}{l}\text { \% Of all } \\
\text { staff } \\
\text { interviewed }\end{array}$} \\
\hline & Lecturer & $\begin{array}{l}\text { Senior } \\
\text { Lecturer }\end{array}$ & $\begin{array}{l}\text { Associate } \\
\text { professor }\end{array}$ & Professor & $\begin{array}{l}\text { Research } \\
\text { /Senior } \\
\text { research } \\
\text { fellow }\end{array}$ & $\begin{array}{l}\text { Asst. } \\
\text { Lecturer } \\
\text { /Tutor }\end{array}$ & $\begin{array}{l}\text { All others } \\
\text { (Admin staff) }\end{array}$ & & & & & \\
\hline $\mathrm{BEOH}$ & 3 & 0 & 0 & 1 & 2 & 0 & 2 & 8 & 2 & 10 & 6 & $60 \%$ \\
\hline Biostatistics & 1 & 0 & 0 & 0 & 0 & 3 & 2 & 6 & 7 & 13 & 7 & $54 \%$ \\
\hline EPDC & 4 & 1 & 1 & 1 & 0 & 0 & 2 & 9 & 16 & 25 & 11 & $44 \%$ \\
\hline HPPM & 1 & 2 & 0 & 0 & 0 & 2 & 2 & 7 & 6 & 13 & 12 & $92 \%$ \\
\hline PFRH & 5 & 1 & 1 & 0 & 0 & 0 & 3 & 10 & 0 & 10 & 6 & $60 \%$ \\
\hline SOBS & 1 & 1 & 0 & 0 & 1 & 0 & 4 & 7 & 4 & 11 & 6 & $55 \%$ \\
\hline Accounts & 0 & 0 & 0 & 0 & 0 & 0 & 6 & 6 & 0 & 6 & 4 & $67 \%$ \\
\hline Administration & 0 & 0 & 0 & 0 & 0 & 0 & 12 & 12 & 0 & 12 & 11 & $92 \%$ \\
\hline On leave & 0 & 0 & 0 & 0 & 0 & 0 & 6 & 6 & 0 & 6 & 0 & $0 \%$ \\
\hline Missing & & & & & & & & & & & 4 & \\
\hline TOTAL & 15 & 5 & 2 & 2 & 3 & 5 & 39 & 71 & 35 & 106 & 67 & $63 \%$ \\
\hline$\%$ Of all full time staff & $21 \%$ & $7 \%$ & $3 \%$ & $3 \%$ & $4 \%$ & $7 \%$ & $55 \%$ & $100 \%$ & & & & \\
\hline $\begin{array}{l}\% \text { Of all staff (full and } \\
\text { part time) }\end{array}$ & $14 \%$ & $5 \%$ & $2 \%$ & $2 \%$ & $3 \%$ & $5 \%$ & $37 \%$ & $67 \%$ & $33 \%$ & & & \\
\hline
\end{tabular}

${ }^{1}$ BEOHS=Biological, Environmental and Occupational Health Sciences; EPDC=Epidemiology and Disease Control; HPPM=Health Policy, Planning and Management; PFRH=Population, Family and

Reproductive Health; SOBS-Social and Behavioral Sciences

\section{BOX 1 Individual staff level capacity}

The fields of study at doctoral level for academic staff included adolescent and reproductive health, applied health social science, administration, health policy and administration, epidemiology, population studies, evaluation, health economics, health informatics, immune parasitology, molecular parasitology, nutritional sciences, psychology, public health, and environmental health. 
Table 4 Summary of information from the individual staff questionnaire

\begin{tabular}{|c|c|c|c|c|c|c|}
\hline \multirow[t]{2}{*}{ ITEM } & \multicolumn{3}{|c|}{ Academic staff $(n=34)$} & \multicolumn{3}{|c|}{ Admin \& Non academic staff $(n=33)$} \\
\hline & $\begin{array}{l}\text { Total responses } \\
\text { to question }\end{array}$ & $\begin{array}{l}\text { Total no. Of } \\
\text { respondents }\end{array}$ & $\begin{array}{l}\%(\text { Responses/ total } \\
\text { no. Of } \\
\text { respondents) } * 100\end{array}$ & $\begin{array}{l}\text { Total } \\
\text { responses in } \\
\text { category }\end{array}$ & $\begin{array}{l}\text { Total no. Of } \\
\text { respondents }\end{array}$ & $\begin{array}{l}\%(\text { Responses/ } \\
\text { total no. Of } \\
\text { respondents)*1 } \\
00\end{array}$ \\
\hline \multicolumn{7}{|l|}{ EMPLOYMENT CATEGORIES } \\
\hline Full time staff & 25 & 34 & $74 \%$ & 25 & 32 & $78 \%$ \\
\hline Part time staff & 6 & 34 & $18 \%$ & 1 & 32 & $3 \%$ \\
\hline Contract staff & 3 & 34 & $9 \%$ & 6 & 32 & $19 \%$ \\
\hline \multicolumn{7}{|l|}{ GENDER: } \\
\hline Male & 25 & 34 & $74 \%$ & 11 & 33 & $33 \%$ \\
\hline Female & 9 & 34 & $26 \%$ & 22 & 33 & $67 \%$ \\
\hline \multicolumn{7}{|l|}{ YES I HAVE ADEQUATE ACCESS TO: } \\
\hline Office space & 22 & 34 & $65 \%$ & 17 & 32 & $53 \%$ \\
\hline A computer & 22 & 34 & $65 \%$ & 25 & 33 & $76 \%$ \\
\hline Email and internet & 24 & 34 & $71 \%$ & 29 & 33 & $88 \%$ \\
\hline Electronic resources including online journals & 17 & 32 & $53 \%$ & 11 & 30 & $37 \%$ \\
\hline Teaching space & 21 & 30 & $70 \%$ & 2 & 10 & $20 \%$ \\
\hline Teaching equipment & 15 & 29 & $52 \%$ & 2 & 11 & $18 \%$ \\
\hline \multicolumn{7}{|l|}{ YES I NEED ADDITIONAL TRAINING IN: } \\
\hline What HPSA is & 22 & 32 & $69 \%$ & 6 & 10 & $60 \%$ \\
\hline $\begin{array}{l}\text { What constitutes HPSA approaches to research and } \\
\text { training }\end{array}$ & 27 & 33 & $82 \%$ & 5 & 10 & $50 \%$ \\
\hline Writing research methodologies & 24 & 33 & $73 \%$ & 9 & 11 & $82 \%$ \\
\hline $\begin{array}{l}\text { Writing briefing notes for politicians, policy } \\
\text { makers, external funders and donors }\end{array}$ & 27 & 33 & $82 \%$ & 8 & 10 & $80 \%$ \\
\hline Writing papers for academic journals & 21 & 31 & $68 \%$ & 7 & 10 & $70 \%$ \\
\hline Pedagogy - approaches and methods & 25 & 31 & $81 \%$ & 5 & 8 & $63 \%$ \\
\hline Designing taught courses & 25 & 31 & $81 \%$ & 3 & 7 & $43 \%$ \\
\hline Designing teaching materials & 25 & 31 & $81 \%$ & 4 & 8 & $50 \%$ \\
\hline $\begin{array}{l}\text { Lecturing, student supervision and group } \\
\text { facilitation }\end{array}$ & 22 & 30 & $73 \%$ & 4 & 8 & $50 \%$ \\
\hline Mentoring and coaching others & 25 & 32 & $78 \%$ & 11 & 12 & $92 \%$ \\
\hline Successful negotiation & 25 & 32 & $78 \%$ & 11 & 11 & $100 \%$ \\
\hline Leadership & 24 & 32 & $75 \%$ & 10 & 10 & $100 \%$ \\
\hline Effective networking & 27 & 33 & $82 \%$ & 11 & 11 & $100 \%$ \\
\hline $\begin{array}{l}\text { Identifying and applying for external funding } \\
\text { sources }\end{array}$ & 27 & 33 & $82 \%$ & 10 & 11 & $91 \%$ \\
\hline $\begin{array}{l}\text { Creating and managing effective and efficient } \\
\text { financial reporting systems }\end{array}$ & 24 & 33 & $73 \%$ & 9 & 10 & $90 \%$ \\
\hline $\begin{array}{l}\text { Creating and managing effective internal } \\
\text { information systems }\end{array}$ & 28 & 34 & $82 \%$ & 11 & 11 & $100 \%$ \\
\hline Developing case studies & 28 & 33 & $85 \%$ & 11 & 12 & $92 \%$ \\
\hline Use of qualitative research software & 27 & 33 & $82 \%$ & 9 & 10 & $90 \%$ \\
\hline Use of quantitative research software & 25 & 33 & $76 \%$ & 8 & 9 & $89 \%$ \\
\hline Yes I do teaching related to HPSA & 4 & 33 & $12 \%$ & 1 & 12 & $8 \%$ \\
\hline Yes I conduct research related to HPSA & 4 & 25 & $16 \%$ & 1 & 7 & $14 \%$ \\
\hline
\end{tabular}


Figures 5 and 6 summarize the responses to a series of "do you think you need additional training in any of the following" questions requiring "yes/no" responses. There was variation in top scoring items between academic versus non-academic and administrative staff. Items related to governance like leadership and negotiation attracted more "yes" responses from the non-academic and administrative staff; while the academic staff had more frequent "yes" responses on items related to technical capacity like writing briefs and developing case studies.

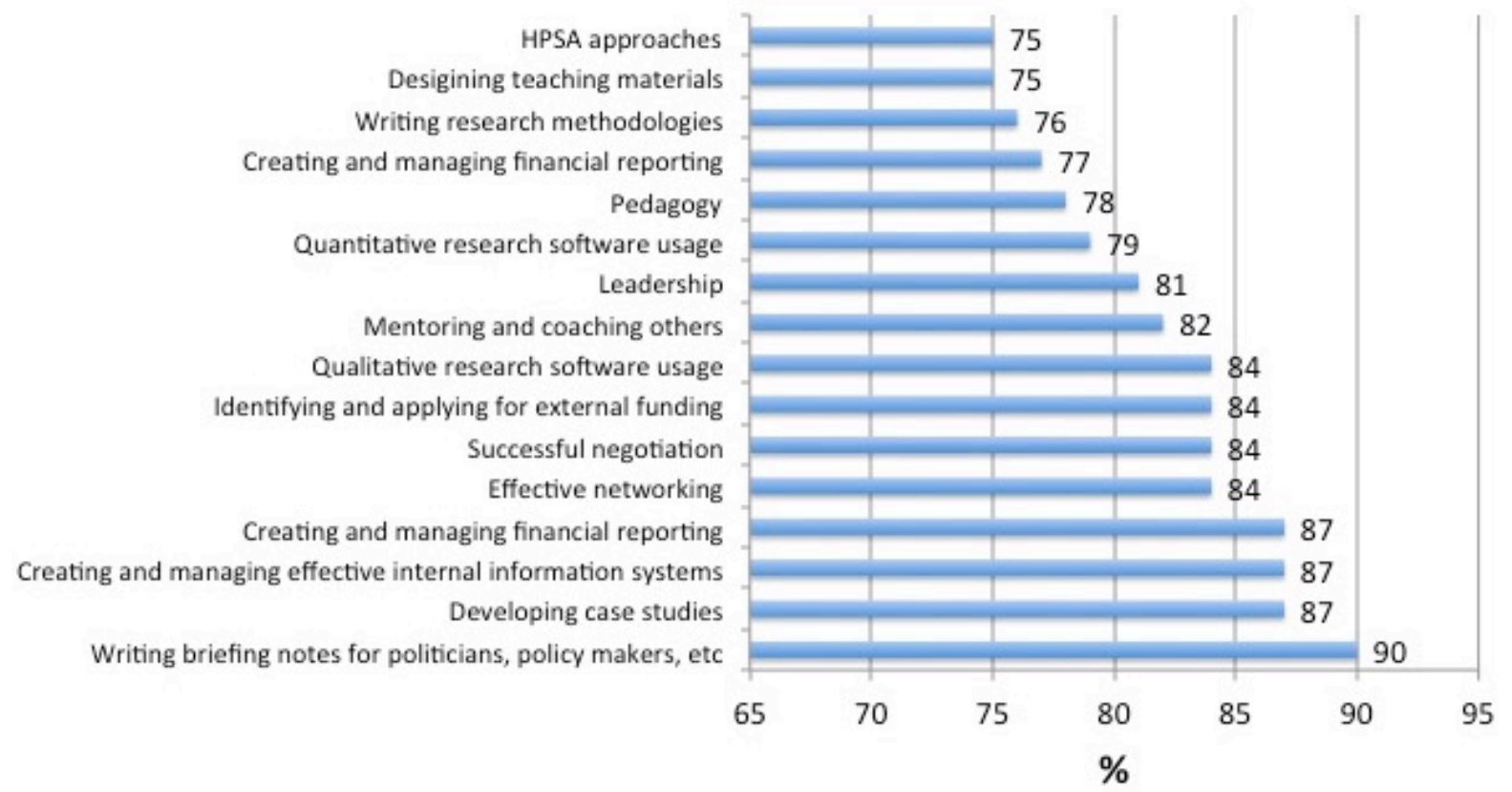

Figure 5 Percent academic staff answering "yes" to the question "Do you think you need additional training in any of the following areas"

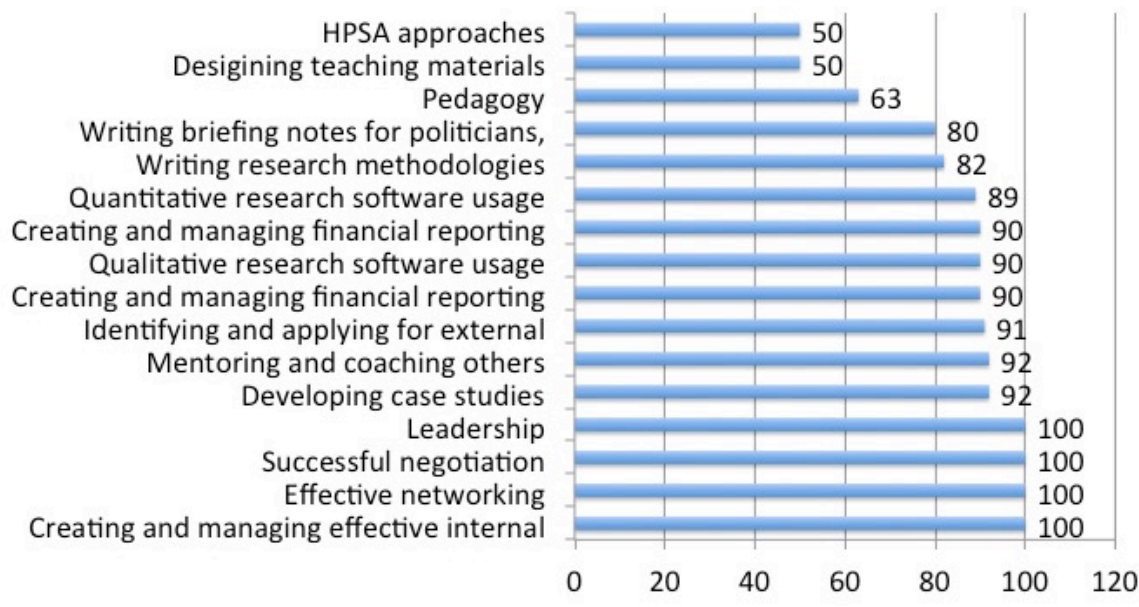

Figure 6 Percent non academic staff answering "yes" to the question "Do you think you need additional training in any of the following areas"

About 54\% of SPH staffs were aware of career development opportunities in the School. These career development opportunities were further studies (locally and abroad), conferences and workshops, refresher courses, exchange programmes, short courses and on- the-job-training. Identified opportunities to strengthen HPSR \&A teaching and conduct were short and longterm training; mentoring and coaching; and development of a specialist master's programme in HPSR\&A. 


\section{DISCUSSION AND CONCLUSIONS}

There exists some capacity for HPSR\&A teaching and conduct in Ghana at all levels, and this is an asset. Also an asset, the School of Public Health since its inception has acknowledged the importance of health policy, planning and management and in creating a HPPM department provided a home for the further development of HPSR\&A. There are also well laid out and stable University governance structures within which the SPH operates.

Alongside these assets are challenges. At all levels, HPSR\&A capacity in Ghana could be described as somewhat fragile. This reflects in part contextual challenges related to national per capita income and priorities that in their turn drive institutional financial, human, infrastructure and resource constraints. This situation is not unique to Ghana. The capacity assessments in all the African universities that are part of CHEPSAA showed that apart from the three institutes in South Africa that did not report significant infrastructural constraints, the institutes in Nigeria, Tanzania and Kenya, like the UG-SPH reported some challenges with unreliable electricity, internet and inadequate teaching aids and space. ${ }^{27}$

Universities in Ghana as in several other parts of subSaharan Africa; have challenges in attracting and retaining adequate numbers of skilled and experienced research and academic staff for a variety of reasons. It is not difficult for highly trained and skilled researchers and academics to be mobile internationally as well as within the country, and between academia and other areas such as professional practice in government, NGO and international organizations. Where there are income gradients between academia and other employment opportunities, and bureaucratic procedures daunting, academia may suffer.

The fragility also reflects in part the fact that despite growing prominence; the field of Health Policy and Systems Research and Analysis (HPSR\&A) remains relatively an emerging discipline still carving its path to growth, development, recognition and adequate resources. This can influence the ability to attract and grow the needed next generation of individuals and institutions in the field. Role modelling and perceptions of the future potential for advancement are important in attracting young and talented individuals into any discipline. Understaffing can bring about heavy workloads and high teacher student ratios making it difficult for staff to find time for research related activities such as proposal development, attracting grants, research conduct and publication. It may also mean that programs to train the next generation are limited, and even when they exist, supervision may be sub-optimal.

At the time of the study in 2011, there was no structured HPSR\&A related doctoral program in the UG-SPH. A doctoral program with a concentration in different fields within public health including Health Policy, Planning and Management has subsequently been introduced. Plans are also now underway to introduce a professional doctor of Public Health (DRPH) program with a concentration in leadership. These are all efforts that can help to build capacity in the HPSR\&A at the institutional and individual level. There can be "no development without research" 28. At the national and contextual level, the Ministries of Health and Education will need to lead the way.

\section{REFERENCES}

1. Murray C.J.L. and Frenk J. A framework for assessing the performance of health systems. Bulletin of the World Health Organization, 2000 78 (6): pages 717-722

2. Hsiao W.C. What is a Health System? Why Should We Care? Harvard School of Public Health, Cambridge, MA, 2003

3. World Bank. 2007. Healthy Development : The World Bank Strategy for Health, Nutrition, and Population. Washington, DC. Pp 49 (C) World Bank.

https://openknowledge.worldbank.org/handle/1098 6/6843 License: CC BY 3.0 IGO. http://hdl.handle.net/10986/6843 (Oct 11, 2015)

4. Shakrishvili G., Atun R., Berman P. et al Converging Health Systems Frameworks: Towards A Concepts-to-Actions Roadmap for Health Systems Strengthening in Low and Middle Income Countries. Global Health Governance 2000, Volume iii, no. 2

5. Smith P.C., Mossialos E., Papanicolas I., Leatherman S.. Performance Measurement for Health System Improvement - Experiences, Challenges and Prospects. Health Economics, Policy and Management. 2009. Part 1: Principles of performance management. Pp 3-7. European Observatory on Health Systems and Policies. Cambridge University Press. downloadable from: http://www.euro.who.int/_data/assets/pdf_file/00 07/135970/E94887_Part_I.pdf (Oct 11, 2015)

6. van Olmen J., Criel B., van Damme W., et al. Analyzing Health Systems To Make Them Stronger. Studies in Health Services Organisation \& Policy, 27. 2010. Downloadable from http://www.strengtheninghealthsystems.be/doc/SH SO\&P27_HS\%20ANALYSIS_FINAL.pdf (Oct 11, 2015) 
7. WHO Everybody's business: strengthening health systems to improve health outcomes: WHO's framework for action 2007

8. WHO. World Health Report 2000. Health Systems: Improving Performance

9. What is Health Policy and Systems Research and why does it matter? Alliance for Health Policy and Systems Research, World Health Organization. $2007 . \quad$ Downloadable from: http://www.who.int/alliancehpsr/resources/Alliance $\% 20 H P S R \% 20$ $\% 20$ Briefing $\% 20$ Note $\% 201$.pdf (Oct 11, 2015)

10. Sheikh K., Gilson L., Agyepong I.A., et al. Building the Field of Health Policy and Systems Research: Framing the Questions. PLoS Med $\begin{array}{llll}2011 & 8 & (8): & \text { e1001073. }\end{array}$ Doi:10,1371/journal.pmed.1001073

11. Gonzalex Block M., Mills A. (2003) Assessing capacity for health policy and systems research in low and middle income countries. Health Research Policy and Systems. December 2003. 1:1. http://link.springer.com/article/10.1186/14784505-1-1

12. Adam T., Ahmad S., Bigdeli M., et al Trends in health policy and systems research over the past decade: still too little capacity in low income countries. PLoS One 2011. 6: e27263

13. Institutes of Medicine. The Future of Public Health. National Academy Press. 1988. Washington D.C.

14. Oxford Advanced Learners dictionary. http://www.oxforddictionaries.com/definition/engl ish/capacity

15. UNDP Capacity Assessment Practice Note. New York, USA. United Nations Development Program. 2008

16. Milen A. What do we know about capacity building? An overview of existing knowledge and good practice. Department of Health Services Provision, World Health Organization, Geneva. 2001

17. LaFond A.K., Brown L., MacIntyre K. Mapping capacity in the health sector: a conceptual framework. The International Journal of Health Planning and Management 2002. 17 (1): pp3 - 22

18. Boffin N. Health System Capacity Building: review of the literature. DGOS - AIDS IMPULS PROGRAM 97203 BVO. Draft Version October 2002. Institute of Tropical Medicine, Antwerp.
Downloadable

from:

http://www.itg.be/itg/uploads/publichealth/Review $\% 20$ health $\% 20$ system $\% 20$ capacity $\% 20$ building.pd $\mathrm{f}($ Oct 11,2015$)$

19. UNDP (2006) Capacity Development Practice Note. United Nations Development Program. http://www.undp.org/c[r/iasc/content/docs/UNDP_ Capacity_Development.pdf

20. Bennett S. \& Green A. Editors Sound Choices: enhancing capacity for evidence informed health policy. 2007. Alliance for Health Policy and Systems Research. Geneva WHO

21. Potter C. and Brough R. Systemic Capacity Building: a hierarchy of needs. Health Policy and Planning 2004. 19 (5) pp 336 - 345

22. Cooke J. A framework to evaluate research capacity building in health care. BMC Family Practice 2005, 6:44 doi:10.1.1186/1471-2296-644

23. Eva Shiffer. Net-Map toolbox. Influence mapping of social networks. http://netmap.wordpress.com/ (Oct 11, 2015)

24. Act 454 of 1993 of the Parliament of the Republic of Ghana. Downloadable from: http://www.ncte.edu.gh/index.php/about-us/thenew-act (Oct 11, 2015)

25. MOH Five Year Program of Work 2007 - 2011. Pp30. Unpublished document. Obtainable from MOH Ghana, Private Mail Bag, Accra, Ghana. Downloadable from: http://www.mohghana.org/UploadFiles/Publications/5Yr\%20POW \%20III\%20(2007-2011)120422153555.pdf (Oct 11, 2015)

26. MOH Health Sector Priorities for 2012. Downloadable from: http:/www.mohghana.org/otherpages.aspx?id=10 (Oct 11, 2015)

27. Mirzoev Tolib., Le Gillian, Green Andrew, et al Assessment of capacity for Health Policy and Systems Research and Analysis in seven African universities: results from the CHEPSAA project. Health Policy and Planning 2013 doi: 10.1093/heapol/czt065. First published online: September 14, 2013

28. Global Forum for Health Research. Yvo Nuyens. No Development without research, 2005. Downloadable from: http:/www.sdh-net.eu/data/uploads/publicationslibrary/no-development-without-research.pdf Oct 2015) 